\title{
Análise da influência de telas utilizadas como reforço em revestimento de argamassa de fachada frente a esforços de tração
}

\section{Analysis of the influence of meshes used as reinforcement for mortar coating of facades on the tensile strength}

\author{
Beatriz Schimelfenig ${ }^{1}$, Francine Padilha ${ }^{1}$, \\ Jonas Demoliner Bordin ${ }^{1}$, Cristina Vitorino da Silva ${ }^{1}$,
}

\footnotetext{
${ }^{1}$ Universidade Regional Integral do Alto Uruguai e das Missões - URI Erechim, RS-331, Erechim, RS, Brasil. e-mail: beatrizschimelfenig@gmail.com, francine.padilha1609@gmail.com, jonas.bordin@hotmail.com, cristina@ uricer.edu.br
}

\section{RESUMO}

Descolamentos e fissuras são manifestações patológicas recorrentes em revestimentos de fachadas de edificações brasileiras. Neste contexto, sabe-se que o revestimento de argamassa ainda é o mais utilizado no mercado da construção civil e tem demonstrado diversos problemas decorrentes dos materiais e da execução de maneira inadequada. Portanto, o presente trabalho buscou avaliar a influência do uso de diferentes telas como reforço de revestimento argamassado, com o objetivo de identificar qual apresenta o melhor desempenho. Foram utilizados três modelos de telas, dois metálicos galvanizados de diferentes malhas e espessuras e um modelo de polietileno de alta densidade (PEAD). A fim de caracterizar a tela isoladamente quanto à resistência à tração, foi realizado o ensaio de tração simples em corpos de prova de 250x300 mm para cada modelo de tela. Para avaliar seu comportamento em conjunto com a argamassa, foi realizado o ensaio de tração na flexão de 4 pontos em corpos de prova prismáticos de 200x500 mm, no qual foram inseridas amostras das telas nas posições de 15,25 e $30 \mathrm{~mm}$ da base para um corpo de prova com espessura de $50 \mathrm{~mm}$. Os resultados obtidos indicam que a tela metálica eletrosoldada galvanizada, de malha quadrada $25 \times 25 \mathrm{~mm}$ e fio de 1,24 mm, apresentou o melhor desempenho dentre os modelos testados.

Palavras-chave: Manifestações Patológicas; Revestimento de Argamassa; Telas; Resistência à Tração.

\begin{abstract}
Displacement and fissures are recurrent pathological manifestations in the facade coating of brazilian buildings. In this context, it is known that mortar coating is still the most used in the civil construction market and has demonstrated several problems due to inappropriate employment and execution. Therefore, the present work aimed to evaluate the influence of different meshes as reinforcement for mortar coating, in order to identify which one present the best performance. It was used three mesh models, two made of galvanized metal with different meshes and thicknesses and one made of high-density polyethylene. In order to isolated characterize the meshes for tensile strength, it was performed the tensile assay in specimens of 250x300 mm for each mesh models. To evaluate the influence of the different meshes in conjunction with the mortar, the tensile test in bending at 4 points in specimens of 200x500 mm was carried out, where the meshes were inserted at 15, 25 and $30 \mathrm{~mm}$ from the bottom of the specimen with $50 \mathrm{~mm}$ thickness. The data indicate that the square $25 \times 25 \mathrm{~mm}$ and $1.24 \mathrm{~mm}$ wire galvanized metal mesh presented the best performance among the tested models.
\end{abstract}

Keywords: Pathological Manifestations; Mortar Coating; Meshes; Tensile Strength.

\section{INTRODUÇÃO}

A crescente verticalização das cidades torna os edifícios mais altos e com isso mais flexíveis, fazendo com 
que os revestimentos externos trabalhem de forma diversificada. Com isso surgem inúmeras manifestações patológicas causadas por falhas de projeto e de execução, como fissuras por movimentação térmica diferencial e descolamentos em placas [1]. A utilização de revestimentos argamassados reforçados com tela é descrita na literatura como uma forma de minimizar esses tipos de manifestações patológicas [2, 9], entretanto ainda é uma prática pouco usual no Brasil e, muitas vezes, desconhecida pelos projetistas, sendo que a única norma brasileira que identifica um tipo de material a ser utilizado para essa finalidade é a NBR 13755 [3]. Segundo a norma NBR 13755 [3], a principal função da tela é coibir a retração do revestimento argamassado. Além de suportar o peso próprio de todas as camadas a partir do chapisco, sua presença é indispensável quando uma das camadas for uma impermeabilização ou um isolamento térmico. As telas funcionam como um elemento que além de acrescer a capacidade resistente à tração do revestimento, distribui tensões pontuais por toda sua extensão, fazendo o que seria uma grande abertura se transformar em inúmeras microfissuras, que em diversos casos são imperceptíveis e não causariam problemas ao revestimento [4]. Esse reforço pode ser executado de duas formas, como ponte de transição, quando utilizado entre a alvenaria e a estrutura, ou como argamassa armada, nos casos em que o revestimento apresenta espessuras elevadas. Salienta-se que não existe um ensaio normatizado a fim de caracterizar o desempenho de argamassas armadas.

Logo, a proposta desse trabalho é avaliar três diferentes modelos de telas, a fim de verificar qual terá o melhor desempenho quando utilizada como reforço no revestimento de argamassa. Para tanto, as telas foram caracterizadas frente ao ensaio de tração, enquanto que para avaliar a tela imersa na camada de argamassa foi utilizado o ensaio de tração na flexão a quatro pontos.

\section{MATERIAIS E MÉTODOS}

O programa experimental deste trabalho, apresentado na Figura 1, foi planejado de forma a trabalhar com fatores controláveis (tipo de tela e posição da tela no corpo de prova de argamassa) para posteriormente avaliar a influência de cada um destes fatores nas variáveis de resposta (resistência à tração da tela e resistência à tração na flexão das argamassas armadas).

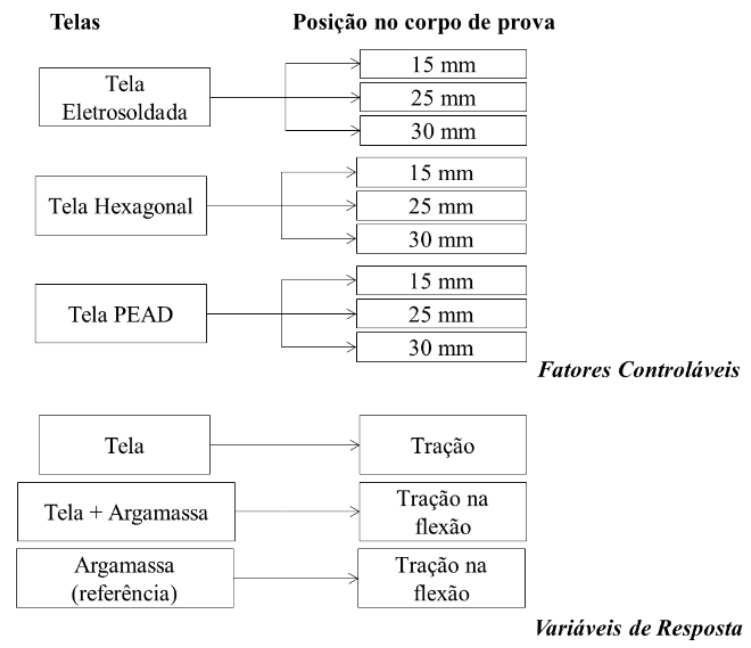

Figura 1: Programa experimental.

\subsection{Materiais}

Para a argamassa optou-se por utilizar uma industrializada com fibras para revestimento de fachada, devido ao fato de existir menos interferência na dosagem, bastando apenas a adição de água na proporção indicada. Além disso, é um tipo de argamassa que está ganhando bastante mercado por proporcionar maior resistência a fissuras por retração.

Neste trabalho foram adotados dois tipos de telas metálicas e uma de polietileno de alta densidade (PEAD). A tela eletrosoldada galvanizada, apresentada na Figura 2 (a), é empregada especialmente nos reforços ou estruturação de revestimentos argamassados, possuindo arames de bitola de 1,24 mm, malha de $25 \times 25 \mathrm{~mm}$, resultando em uma taxa de aço de $0,776 \mathrm{~kg} / \mathrm{m}^{2}$, segundo seu fabricante. Sua comercialização é feita em rolos com $25 \mathrm{~m}$ de extensão e largura de $50 \mathrm{~cm}$. A tela hexagonal tipo "pinteiro", apresentada na Figura 2 (b), não é recomendado pelo fabricante para o uso no reforço da camada de revestimento, porém 
vem sendo muito utilizada entre os construtores por ser de fácil acesso e ter baixo custo. Possui abertura de malha de 1", diâmetro de fio de $0,71 \mathrm{~mm}$ com camada leve de zinco. Sua comercialização é feita em rolos de $50 \mathrm{~m}$ de comprimento e largura de 1,0 ou 1,5 metros. A tela extrusada PEAD, apresentada na Figura 2 (c), foi desenvolvida para substituir as telas metálicas em reforços de argamassa. Possui abertura de malha de $13 \mathrm{~mm}$, diâmetro de fio de $0,40 \mathrm{~mm}$ e é comercializada em rolos com largura de 1,0 metro e comprimento de $50 \mathrm{~m}$.

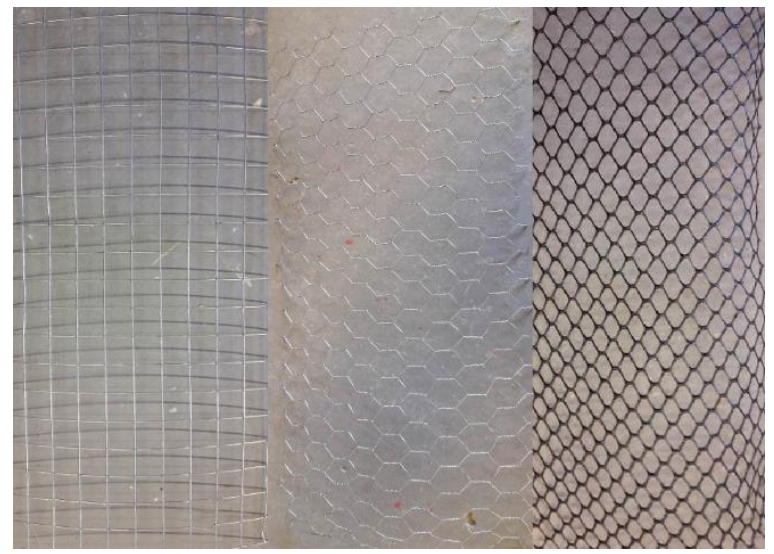

(a)

(b)

(c)

Figura 2: Telas: (a) Tela eletrosoldada galvanizada, (b) Tela hexagonal e (c) Tela PEAD.

\subsection{Métodos}

\subsubsection{Ensaio mecânico de tração das telas}

A fim de verificar a resistência das telas à tração, esse ensaio propõe submeter corpos de prova de dimensões 250x300 mm a um esforço de tração aplicado na direção longitudinal, alongando-o até a sua ruptura. Tal metodologia busca contemplar o proposto por ANTUNES et al. (2013) [5]. Foram utilizadas seis amostras de cada tela, retiradas no sentido do rolo, para a execução do ensaio, o qual foi realizado em uma máquina de ensaios universais da marca EMIC, modelo DL 10000.

Para a realização desse ensaio foi desenvolvido um suporte para fixação da tela na máquina de ensaio, que consiste em duas chapas metálicas dobradas, onde as telas são encaixadas e, posteriormente, fixadas com parafusos como mostra a Figura 3. Esse dispositivo possui um pino para ser encaixado na máquina de ensaio, mantendo a tela na vertical para aplicação da força de tração, conforme demonstrado na Figura 4.

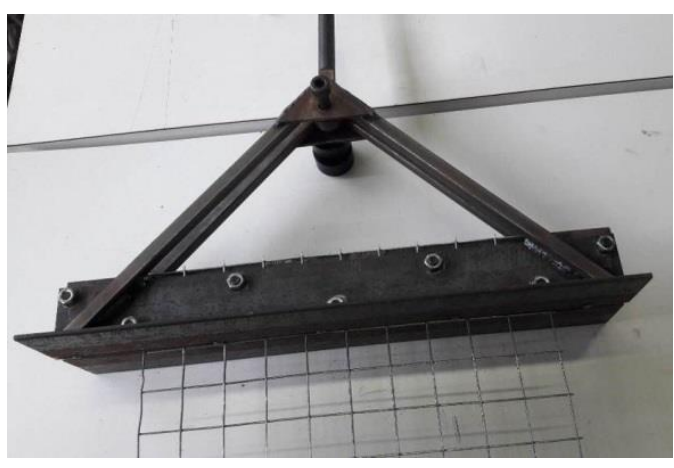

Figura 3: Suporte para ensaio de tração das telas.

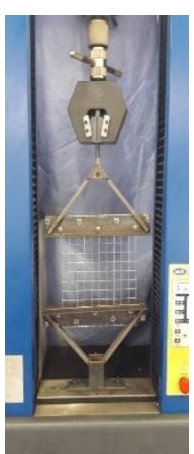

(a)

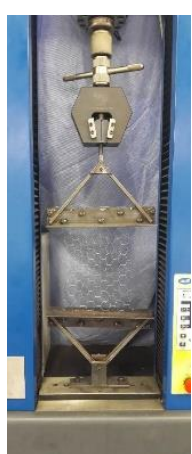

(b)

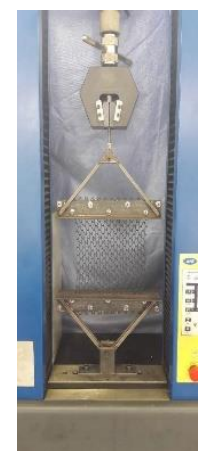

(c)

Figura 4: Realização do ensaio de tração nas telas:

(a) eletrosoldada, (b) hexagonal e (c) PEAD.

\subsubsection{Ensaio mecânico de tração na flexão a quatro pontos}

Para avaliar o desempenho do revestimento de argamassa reforçado com tela, representando o esforço de tensão de tração na flexão, foi realizado o ensaio proposto por ANTUNES et al. (2014) [6], que adota o método de tração na flexão em 4 pontos, baseado na metodologia empregada para caracterização do concreto, descrita na NBR 12142 [7]. Para esse ensaio foram avaliados quatro corpos de prova para cada tipo de tela e 
posição, conforme recomendado por ANTUNES et al. (2014) [6]. Os corpos de prova utilizados eram de 200x500x50 mm, produzidos em fôrmas de compensado plastificado.

Para produção dos corpos de prova foram cortadas 12 amostras de cada tela com 200x500 mm, as quais foram inseridas na metade da camada, e também a $15 \mathrm{~mm}$ e $30 \mathrm{~mm}$ em relação a base do corpo de prova. A moldagem procedeu-se da seguinte forma: após preparar as fôrmas e marcar a altura em que a tela deveria ser colocada, depositou-se a primeira camada de argamassa industrializada e realizaram-se 8 leves golpes com martelo de borracha nos quatro cantos da fôrma; em seguida, a tela foi posicionada sobre essa camada inicial com um leve aperto. Então, foi lançado o restante da argamassa para preencher a fôrma, efetuandose no final 8 golpes leves com martelo de borracha em cada um dos lados da fôrma, a fim de realizar o adensamento e retirar possíveis bolhas. Finalmente, foi realizada a regularização superficial do material com auxílio de régua metálica. Após moldados todos os corpos de prova, os mesmos foram armazenados em câmara climatizada, com temperatura e umidade controladas (temperatura de $23 \pm 2^{\circ} \mathrm{C}$ e umidade relativa de $65 \pm$ $5 \%)$, e desformados após $72 \mathrm{~h}$.

Para avaliar a capacidade do corpo de prova de resistir à ruptura quando submetido ao esforço de tração na flexão, segundo a NBR 13279 [8], adotou-se a velocidade de carregamento de 0,05KN/s.

Segundo ANTUNES et al. (2014) [6], o ensaio de tração na flexão a quatro pontos, o qual possui a carga de aplicação dividida em dois pontos, possibilita maior precisão nos dados obtidos e permite medir as propriedades com resultados mais satisfatórios, comparando-se ao com três apoios. Esse fato ocorre devido o mesmo ser capaz de garantir a aplicação da força perpendicular nas faces superior e inferior da amostra sem promover excentricidades $[6,9]$.

\section{RESULTADOS E DISCUSSÃO}

Para tratamento de possíveis erros foi realizado o descarte dos dados espúrios, através do conjunto de resultados formados entre a média dos resultados mais um desvio padrão e a média menos um desvio padrão. Todos os resultados foram tratados estatisticamente através do método de análise de variância (ANOVA) pelo software Statistica 7.0.

\subsection{Resistência à tração das telas}

Inicialmente buscou-se caracterizar os modelos de telas isoladamente, sendo julgada a ação da tela a partir da metodologia proposta por ANTUNES et al. (2013) [5] para avaliação das telas perante o ensaio de tração. Os resultados encontram-se na Tabela 1.

Tabela 1: Resultados do ensaio de tração das telas.

\begin{tabular}{lccc}
\hline \multicolumn{1}{c}{ Tela } & Carga máxima média (N) & DP & CV \\
\hline Eletrosoldada & 3963,50 & 314,14 & 7,93 \\
Hexagonal & 440,85 & 70,84 & 16,07 \\
PEAD & 224,83 & 39,10 & 17,39 \\
\hline DP: Desvio Padrão & CV: Coeficiente de Variação & &
\end{tabular}

A carga máxima, considerada pela máquina de ensaio, se deu no momento da ruptura do primeiro fio. $\mathrm{Na}$ Tabela 1 observa-se que a tela eletrosoldada mostrou-se capaz de suportar elevada tensão, registrando uma carga máxima média de 3963,50 N, com desvio padrão de 314,14 e coeficiente de variação igual a 7,93. No entanto, a tela hexagonal e PEAD obtiveram valores bem baixos, quando comparados com a eletrosoldada. A tela hexagonal registrou uma carga máxima média de 440,85 N, com coeficiente de variação igual a 16,07 e a tela de PEAD registrou uma carga máxima média de $224,83 \mathrm{~N}$, com coeficiente de variação igual a 17,39. Na Figura 5 pode-se observar a diferença dos valores encontrados. 


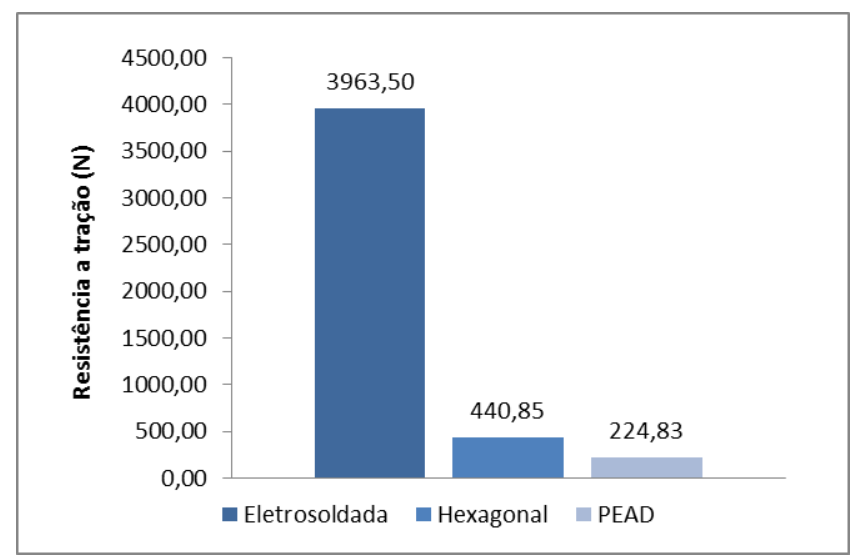

Figura 5: Valores da resistência média à tração para cada modelo de tela.

Durante a realização do ensaio de tração, observou-se a deformação das telas, sendo a tela eletrosoldada a menos deformável, seguida da tela hexagonal e PEAD. Isso ocorre pela tela eletrosoldada ter maior espessura de fio, além do próprio processo de soldagem, já a tela hexagonal tem menor espessura de fio e é trançada, enquanto que a tela PEAD é fabricada com material flexível.

Com os valores obtidos foi realizada uma análise estatística para verificar se há diferença significativa entre os valores médios encontrados para cada modelo de tela. Os resultados foram analisados estatisticamente através do método ANOVA e seu resultado encontra-se na Tabela 2.

Tabela 2: Análise da variância (ANOVA) - Resistência à tração das telas.

\begin{tabular}{lccccc}
\hline & GDL & MS & F(calc) & P & Significância \\
\hline Tela & 2 & 14426714,27 & 531,81 & 0,000000003 & S \\
Erro & 8 & 27127,46 & - & - & - \\
\hline
\end{tabular}

GDL: Graus de Liberdade (n-1) MS: Média Simples F(calc): Valor calculado de F

p: nível de significância S: valor significativo NS: valor não significativo

Se $\mathrm{p}<5 \%$ : valor significativo

De acordo com a Tabela 2, verifica-se que o tipo de tela utilizado foi significativo na resistência à tração. Na Figura 6, pode-se avaliar a queda de resistência à tração entre os diferentes tipos de telas utilizados nos ensaios.

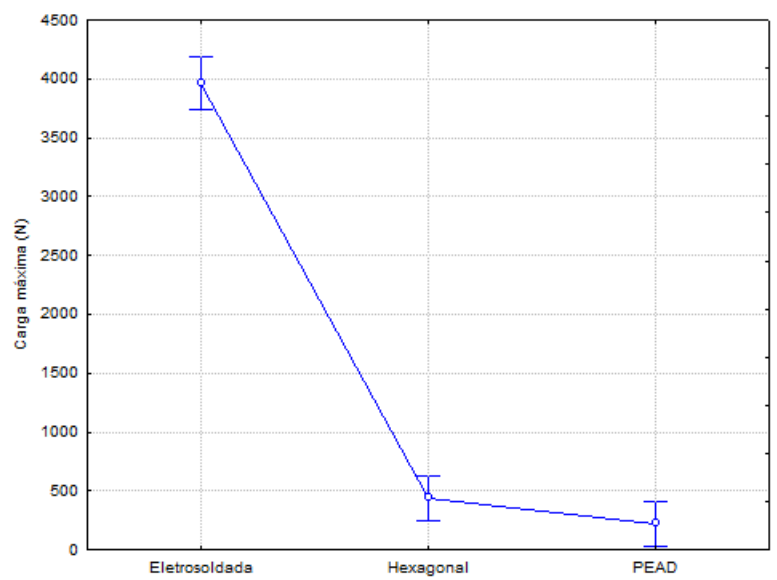

Figura 6: Comparação entre as telas utilizadas no ensaio de tração.

Com a análise da Figura 6 foi identificado que a tela hexagonal e a PEAD não possuem diferença sig- 
nificativa entre seus resultados, e a tela eletrosoldada teve resultados bem superiores. Segundo POZZOBON e ROVEDDER (2014) [10], a tela eletrosoldada é capaz de suportar altas tensões mantendo seus resultados constantes, além de baixa deformação, o que é uma característica importante a se considerar na utilização de telas no reforço de revestimentos argamassados.

\subsection{Resistência à tração na flexão dos corpos de prova reforçados com tela}

Após os 28 dias da moldagem dos corpos de prova, realizou-se o ensaio de tração na flexão da argamassa armada, sendo aplicada sobre os mesmos uma carga contínua até a sua ruptura. Na Tabela 3 são apresentadas as médias dos resultados do ensaio.

Tabela 3: Resultados do ensaio de tração na flexão das argamassas armadas.

\begin{tabular}{lccccc}
\hline \multicolumn{1}{c}{ Tela } & $\begin{array}{c}\text { Posição } \\
(\mathbf{c m})\end{array}$ & $\begin{array}{c}\text { Carga de ruptura média } \\
\mathbf{( N )}\end{array}$ & $\begin{array}{c}\text { Tensão de tração na flexão } \\
\text { média (MPa) }\end{array}$ & DP & CV (\%) \\
\hline Eletrosoldada & 1,5 & 1953,40 & 1,76 & 0,004 & 0,25 \\
Eletrosoldada & 2,5 & 1828,65 & 1,44 & 0,46 & 32,01 \\
Eletrosoldada & 3,0 & 1909,45 & 1,79 & 0,16 & 8,92 \\
Hexagonal & 1,5 & 1396,27 & 1,26 & 0,07 & 5,28 \\
Hexagonal & 2,5 & 1305,63 & 1,18 & 0,28 & 23,49 \\
Hexagonal & 3,0 & 1276,10 & 1,15 & 0,12 & 10,80 \\
PEAD & 1,5 & 1456,33 & 1,31 & 0,16 & 12,40 \\
PEAD & 2,5 & 1296,15 & 1,17 & 0,01 & 0,69 \\
PEAD & 3,0 & 1533,25 & 1,38 & 0,19 & 14,00 \\
Referência & - & 1658,15 & 1,49 & 0,28 & 19,01 \\
\hline
\end{tabular}

DP: Desvio Padrão CV: Coeficiente de Variação

A partir destes resultados pode-se realizar a primeira avaliação da argamassa reforçada com tela, onde é observado que os corpos de prova reforçados com a tela eletrosoldada obtiveram os maiores valores, comparativamente às demais telas. A tela eletrosoldada teve seu melhor resultado quando utilizada mais afastada da base do corpo de prova, registrando uma resistência à tração na flexão média de $1,79 \mathrm{MPa}$, desvio padrão de $0,16 \mathrm{MPa}$ e um coeficiente de variação igual a $8,92 \%$. Esse resultado apresenta um aumento de $20 \%$ em relação ao corpo de prova de referência, o qual não tem o uso de reforço com tela na argamassa.

A tela hexagonal e a tela PEAD se mostraram muito imprevisíveis, pelo fato de possuírem diâmetro de fio menor e grande deformação, o que não é aconselhável como característica da tela para ser usada no reforço de argamassa, além da tela PEAD diminuir a aderência na matriz em função de seu material. Cabe salientar, que o maior resultado de resistência à tração na flexão média para a tela hexagonal foi de $1,26 \mathrm{MPa}$, com coeficiente de variação igual a 5,28\%. Já para a tela de PEAD a maior média foi igual a 1,38MPa, com coeficiente de variação de $14 \%$. Logo, observa-se que os resultados para as duas telas ficaram abaixo do resistido pelo corpo de prova de referência, que apresentou uma média de 1,49MPa. Nas Figuras 7, 8, e 9 é possível verificar um comparativo entre elas. 


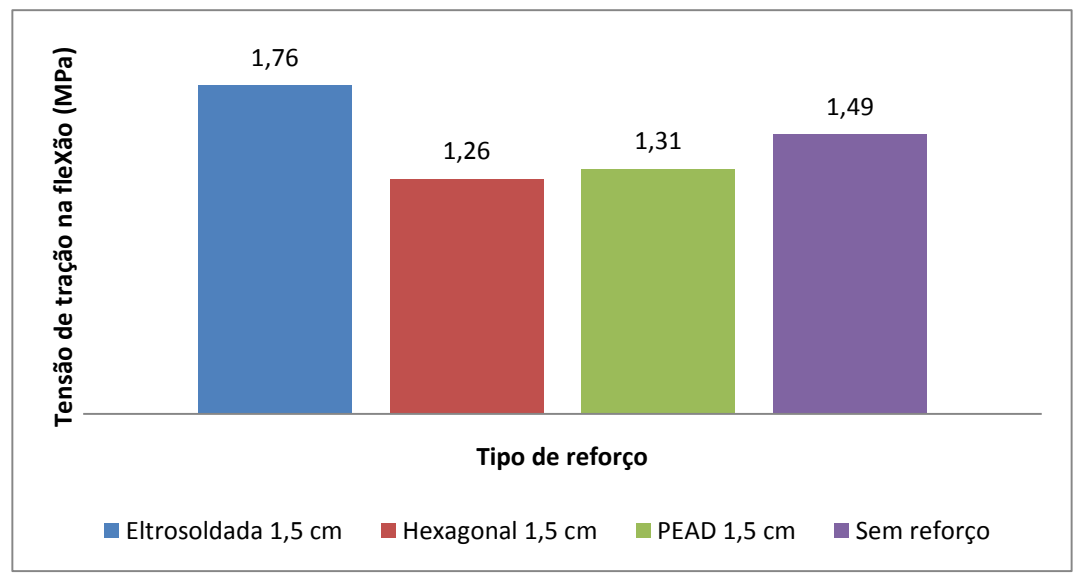

Figura 7: Valores para tensão de tração na flexão na posição $1,5 \mathrm{~cm}$.

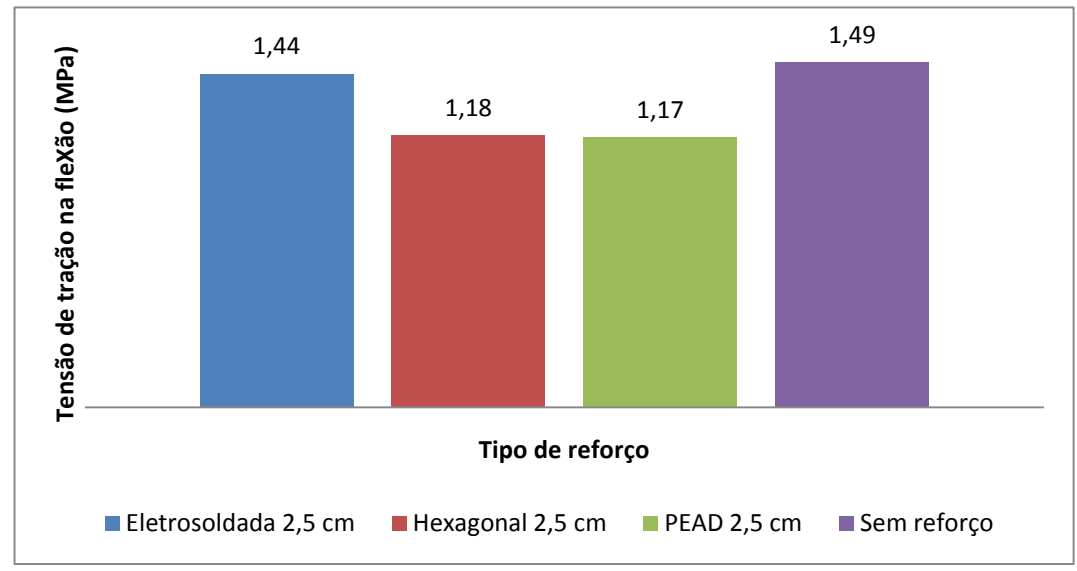

Figura 8: Valores para tensão de tração na flexão na posição $2,5 \mathrm{~cm}$.

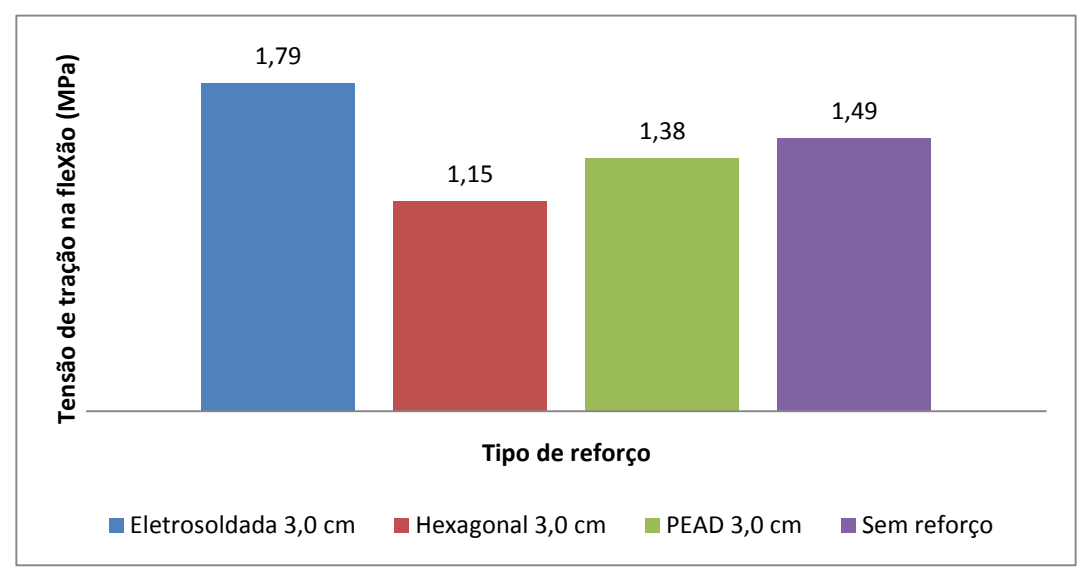

Figura 9: Valores para tensão de tração na flexão na posição $3,0 \mathrm{~cm}$.

Os resultados foram analisados estatisticamente através da ANOVA. A análise buscou verificar se há diferença significativa entre os valores encontrados para a tensão de tração na flexão para cada tipo de tela utilizada como reforço na argamassa e a posição das telas no corpo de prova. Tal análise encontra-se na Tabela 4 . 
Tabela 4: Análise da variância (ANOVA) - Resistência à tração na flexão das argamassas armadas.

\begin{tabular}{lccccc}
\hline & GDL & MS & F(calc) & $\mathbf{p}$ & Significância \\
\hline Tipo de tela & 2 & 0,46 & 11,64 & 0,001 & S \\
Posição & 2 & 0,08 & 1,93 & 0,182 & NS \\
Tipo de Tela x Posição & 4 & 0,03 & 0,66 & 0,629 & NS \\
Erro & 14 & 0,04 & - & - & - \\
\hline
\end{tabular}

GDL: Graus de Liberdade (n-1) MS: Média Simples F(calc): Valor calculado de F

p: nível de significância $\quad S$ : valor significativo NS: valor não-significativo

Se $\mathrm{p}<5 \%$ : valor significativo

Analisando aos resultados do ANOVA, podemos observar que os diferentes tipos de telas utilizados tiveram influência significativa nos resultados de tração na flexão, já a posição utilizada dentro do corpo de prova não teve essa influência nos resultados. Na Figura 10 pode-se avaliar o efeito de cada tipo de tela e na Tabela 5 estão apresentados os resultados da análise estatística realizada pelo teste de Fisher.

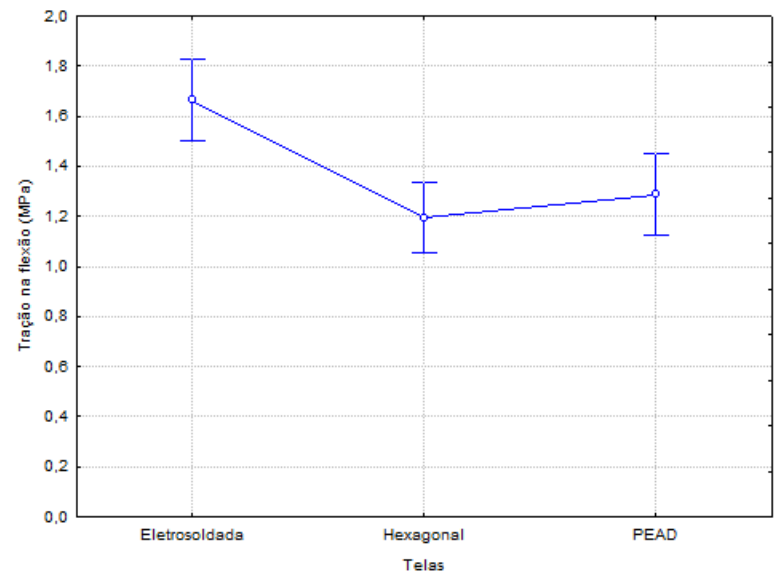

Figura 10: Comparação entre as telas utilizadas no ensaio de tração na flexão a quatro pontos.

Tabela 5: Resultados da interação das telas como reforço do sistema argamassado pelo teste de Fisher.

\begin{tabular}{c|c|c|c}
\hline Tela & Eletrosoldada & Hexagonal & PEAD \\
\hline Eletrosoldada & - & $0,000232(\mathrm{~S})$ & $0,002304(\mathrm{~S})$ \\
\hline Hexagonal & $0,000232(\mathrm{~S})$ & - & $0,352152(\mathrm{NS})$ \\
\hline PEAD & $0,002304(\mathrm{~S})$ & $0,352152(\mathrm{NS})$ & - \\
\hline
\end{tabular}

(S) valor significativo (NS) valor não-significativo $\mathrm{Se} p<5 \%$ : valor significativo

Através da análise realizada pelo método de Fischer, que permite comparar a significância da interação entre os grupos de telas, apenas a tela eletrosoldada demonstrou ser diferente estatisticamente dentre as outras. A interação entre as telas hexagonal e PEAD não apresentou diferença significativa entre seus resultados, sendo estatisticamente iguais quando utilizadas no reforço da argamassa.

Por fim, foram analisados estatisticamente os resultados de tensão de tração na flexão, obtidos para a argamassa reforçada com tela e sua referência, sem o uso do reforço, através do ANOVA. A análise da variância encontra-se na Tabela 6 e a Figura 11 apresenta a comparação entre o corpo de prova de referência e os tipos de reforços utilizados. 
Tabela 6: Análise da variância (ANOVA) - Resistência à tração na flexão para os tipos de tela.

\begin{tabular}{lccccc}
\hline & GDL & MS & F(calc) & $\mathbf{p}$ & Significância \\
\hline Tipo de tela & 3 & 0,36 & 6,70 & 0,002 & $\mathrm{~S}$ \\
Erro & 23 & 0,05 & & & - \\
\hline
\end{tabular}

GDL: Graus de Liberdade (n-1) MS: Média Simples F(calc): Valor calculado de F

p: nível de significância $\quad$ S: valor significativo $\quad$ NS: valor não-significativo

Se $\mathrm{p}<5 \%$ : valor significativo

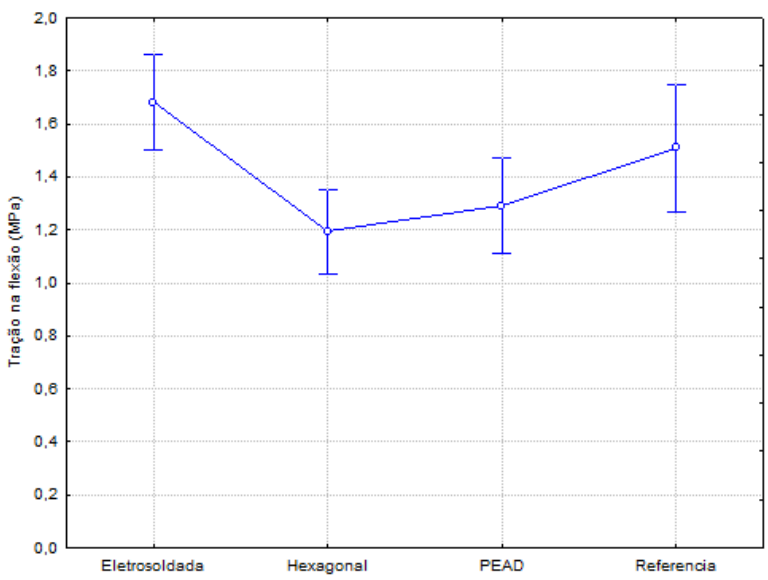

Figura 11: Comparação entre os tipos de reforços utilizados no ensaio de tração na flexão a quatro pontos.

Analisando os resultados apresentados na Figura 11, pode-se observar que apenas a tela eletrosoldada mostrou um aumento de resistência significativo em relação às demais telas utilizadas, no entanto se mostrou estatisticamente igual a referência (sem tela). Segundo POZZOBON e ROVEDDER (2014) [10], a tela eletrosoldada é uma tela rígida, sendo que os esforços gerados pela movimentação do revestimento precisam ser muito elevados para que ocorra o surgimento de fissuras. ANTUNES e MASUERO (2016) [9] avaliaram diferentes tipos de telas no reforço de argamassas para revestimento, onde os resultados encontrados mostraram que o uso da tela eletrosoldada galvanizada de malha quadrada também apresentou comportamento superior às demais frente às análises de resistência à tração na flexão.

As telas hexagonais e PEAD apresentaram desempenho inferior a eletrosoldada, com médias de resistência à tração na flexão da ordem de 1,20 MPa e 1,28 MPa, respectivamente. Isso ocorre, possivelmente, em função dessas telas possuírem baixa resistência do fio e grande deformação, logo, sugere-se que o módulo de deformação das mesmas se assemelha ao módulo da argamassa, assim não ocorrendo a amarração das fissuras e sendo insuficiente para resistir aos esforços causados pela tração na flexão do sistema. Como já observado por POZZOBON e ROVEDDER (2014) [10], as telas hexagonais e PEAD são incapazes de suportar os esforços solicitados pelo revestimento.

\section{CONCLUSÕES}

A partir dos ensaios efetuados, de tração de três tipos de tela e tração na flexão dos corpos de prova de argamassa, pode-se observar que:

- $\quad$ A tela eletrosoldada apresentou melhores resultados frente às análises de tração das telas e de resistência à tração na flexão do revestimento argamassado comparativamente ao uso das demais telas, mostrando-se uma boa opção para o reforço de revestimentos argamassados de fachada.

- A tela hexagonal apresentou o pior desempenho na resistência à tração na flexão dentre os três tipos de telas empregadas, e se mostrou instável no ensaio de tração, pelo fato dos fios serem muito finos e trançados ao invés de soldados. 
- $\quad$ A tela PEAD também mostrou comportamento insatisfatório nas análises de resistência à tração na flexão, sendo assim a menos aconselhável para se utilizar no reforço de revestimento argamassado.

- $\quad$ A posição de utilização da tela no reforço dos corpos de prova de argamassa não mostrou alterações significativas sobre o parâmetro avaliado.

Em suma, este trabalho obteve resultados que indicam a necessidade da utilização de tela como reforço de argamassas de revestimento pelo mercado da construção civil, bem como a importância da sua caracterização antes da escolha do tipo mais adequado a ser empregado.

\section{BIBLIOGRAFIA}

[1] GOMES, A.O., NEVES, C. M. M. "Projeto de execução do sistema de revestimento: uma contribuição prática", In: $5^{\circ}$ Simpósio Brasileiro de Tecnologia das Argamassas, pp. 95-110, São Paulo, Brasil, ANTAC, 2003.

[2] BAUER, R. J. F. Falhas em revestimentos. L. A. Falcão Bauer. (Org.). Materiais de construção. 5ed. Rio de Janeiro, LTC, v. 2, pp. 903-945, 2010.

[3] ASSOCIAÇÃO BRASILEIRA DE NORMAS TÉCNICAS, Rio de Janeiro NBR 13755: 1997 - Revestimento de paredes externas e fachadas com placas cerâmicas e com utilização de argamassa colante.

[4] SILA, A. J. C, "Discussão de elementos para reforço de argamassas de revestimento para fachada", In: $4^{\circ}$ Congresso Português de Argamassas e Etics, Coimbra, Portugal, UC, 2012.

[5] ANTUNES, G. R., SILVA, K. K.., MASUERO, A.B. "Estudo comparativo de resistência à tração em telas metálicas adotadas no reforço de argamassa", In: 55 Congresso Brasileiro do Concreto, 1753-1762, Gramado, Brasil, IBRACON, CBC, 2013.

[6] ANTUNES, G. R., MASUERO, A. B., MAÇANEIRO, M. N. "Avaliação do desempenho de argamassa reforçada com tela metálica através do ensaio de tração na flexão", In: XV Encontro Nacional de Tecnologia do Ambiente Construído, 1753-1762, Maceió, Brasil, ENTAC, 2014.

[7] ASSOCIAÇÃO BRASILEIRA DE NORMAS TÉCNICAS, Rio de Janeiro NBR 12142: 2010 - Concreto -Determinação da resistência à tração na flexão de corpos de prova prismáticos.

[8] ASSOCIAÇÃO BRASILEIRA DE NORMAS TÉCNICAS, Rio de Janeiro NBR 13279: 2005 - Argamassa para assentamento e revestimento de paredes e tetos - Determinação da resistência à tração na flexão e à compressão.

[9] ANTUNES, G. R., MASUERO, A. B. "Flexural tensile strength in mortar coating reinforced with diferente types of metal mesh: A statistical comparison", Construction and Building Materials, v. 121, p. $559-568,2016$.

[10] POZZOBON, M. A., ROVEDDER, A. C. "Verificação das características de revestimentos argamassados reforçados com telas metálicas frente a esforços de tração", In: XXVI Congresso Regional de Iniciação Científica e Tecnológica em Engenharia, 343, Alegrete, Brasil, CRICTE, 2014. 